\title{
Collaborative Modeling in Neuroscience: Time to Go Open Model?
}

\author{
Erik De Schutter
}

Published online: 14 March 2013

(C) Springer Science+Business Media New York 2013

Computational modeling in neuroscience has traditionally followed the 'single researcher's project' approach. Building a model and using it to investigate a scientific question is often the work of one scientist or, at most, of a few people working closely together in one research group. This is quite similar to how most experiments are still being done in neuroscience, where, typically, each student or postdoc have their 'own' project. But the rest of biology has been evolving away from this modus operandi. Especially since the success of Human Genome Project the consortium-based research approach is commonly used to tackle complex problems. Slowly such large-scale 'anonymous' research projects are also finding their way into neuroscience ${ }^{1}$ and into computational neuroscience. The most famous - and controversial - example of the latter is the Blue Brain Project, which uses a supercomputer infrastructure to simulate the cortical column. ${ }^{2}$ But while the Blue Brain Project and other similar initiatives ${ }^{3}$ involve consortia of collaborating researchers, the projects have been closed to outsiders.

Several new initiatives promote a different approach to model building, similar to the open source development of computer code. While open source software is often mainly seen as 'free', more importantly in the context of this editorial, it is usually also understood to be developed in a public,

\footnotetext{
${ }^{1}$ Markram, H. (2007) Bioinformatics: industrializing neuroscience. Nature 445, 160-161.

${ }^{2}$ http://bluebrain.epfl.ch; Newsmaker interview: Henry Markram. (2011) Blue Brain founder responds to critics, clarifies his goals. Interview by Greg Miller. Science 334, 748-749.

${ }^{3}$ Lang, S., Dercksen, V. J., Sakmann, B. \& Oberlaender, M. (2011) Simulation of signal flow in 3D reconstructions of an anatomically realistic neural network in rat vibrissal cortex. Neural Netw 24, 998-1011.

E. De Schutter $(\bowtie)$

Computational Neuroscience Unit, Okinawa Institute of Science and Technology, Okinawa, Japan

e-mail: erik@oist.jp
}

collaborative manner. A first example of open source code development in computational neuroscience was the GENESIS simulator ${ }^{4}$ and a more recent example is the NEST simulator. $^{5}$ A full comparison of these two simulators and how they are being developed is beyond the scope of this editorial, but the different ways in which they organize collaborative development reflects global trends in the open source movement (e.g. the need to police Wikipedia ${ }^{6}$ ). Where GENESIS code development was unstructured, both at the human and at the IT end, NEST development is controlled by an association, the NEST Initiative, and uses modern IT tools ${ }^{7}$ like version control and continuous integration-based workflows. But despite these differences, the underlying philosophy is identical: code development for large software products is labor intensive and beyond the scope of one laboratory. This can be overcome by collaborative development, with many research groups contributing, and because the list of candidate developers is not known a priori a public, open model promotes the widest involvement.

Similar considerations can be brought to model building. Creating a detailed computational model from scratch takes a lot of time, in my experience at least one man year for a single neuron model. ${ }^{8}$ But recent modeling ambitions are

\footnotetext{
${ }^{4}$ http://www.genesis-sim.org; Bower, J. M. \& Beeman, D. (1998)The book of GENESIS: exploring realistic neural models with the ... (Springer-Verlag New York).

${ }^{5}$ http://nest-initiative.org; Gewaltig, M.-O. \& Diesmann, M. (2007) NEST (NEural Simulation Tool). Scholarpedia 2, 1430.

${ }^{6} \mathrm{http}$ ://en.wikipedia.org; http://www.dailymail.co.uk/news/article1208941/Free-edit-Wikipedia-appoints-volunteer-editors-vet-changesarticles-living-people.html

${ }^{7}$ Baxter, S. M., Day, S. W., Fetrow, J. S. \& Reisinger, S. J. (2006) Scientific software development is not an oxymoron. PLoS Comp Biol 2, e87.

${ }^{8}$ De Schutter, E. \& Bower, J. M. (1994) An active membrane model of the cerebellar Purkinje cell. I. Simulation of current clamps in slice. $J$ Neurophysiol 71, 375-400.
} 
much larger than a single neuron: the field of network simulation has evolved from modeling a few small microcircuits to detailed models of complete cortical areas, ${ }^{9,10}$ or of mini brains ${ }^{11}$ based on (fairly) detailed single neuron models. This requires huge infrastructure, both at the IT end to manage the many different stages involved in building such a model ${ }^{12}$ and at the human end to work on the many bits and pieces required (the Blue Brain Project team consists of about 30 people). Moreover, if one sees a large model as an evolving and dynamic repository of all the data about a particular brain area or system, ${ }^{2}$ it makes sense to open it up so that 'all can contribute', similar to, for example, Wikipedia. ${ }^{6}$

Two recent European initiatives will work towards making open models a reality. The first, is the large and ambitious metamorphosis of the Blue Brain Project into the Human Brain Project, ${ }^{13}$ which was recently selected by the European Commission as one of its flagship projects. ${ }^{14}$ Similar to its ancestor, the Human Brain Project (not to be confused by a similarly named US initiative that was ended in $2006^{15}$ ) will invest a lot of resources in IT development, including a 'Brain Simulation Platform'. But this will now be a more open program meant "to trigger and drive a global, collaborative effort that uses the platforms to address fundamental issues in future neuroscience". The USA may soon launch its own Brain Activity Map Project, ${ }^{16}$ but this would be more focused on providing open data that can be fed into computer simulations than on computational modeling itself.
A much more modest initiative is the Open Source Brain $^{17}$ - "a resource for sharing and collaboratively developing computational models of neural systems" which was launched last year. But at present the focus is really on sharing existing models, the fancy interface does not offer much more than what is already available on ModelDB. ${ }^{18}$ This suggests that the collaborative modeling part may be more challenging to launch effectively.

Collaborative, open modeling is an attractive way to tackle ambitious projects in computational neuroscience and to overcome needless duplication of effort. The latter should probably be the main concern: I am familiar with several research groups that are building 'realistic' network models of cerebellar cortex, something my group is also investing a lot of resources into. ${ }^{19}$ All of these modeling projects are slowed down by a lack of properly trained scientists and by a fragmentation of the available data, so the rational solution would be to work together on a single collaborative model. By making the model an open resource there would be no need to have detailed agreements about the use of the model in research and, as mentioned before, it would automatically invite other interested parties to join the collaboration. But, while the initiatives mentioned are steps in the right direction, I do not expect a large take up of open model development soon. Intrinsic conservative attitudes towards data sharing in neuroscience, ${ }^{20,21}$ and model sharing in computational neuroscience ${ }^{22}$ are serious barriers towards adapting this approach. Nevertheless, looking at other fields that are more advanced in sharing like systems biology, ${ }^{22}$ there may be little choice for the larger, ambitious modeling projects to go open model long-term.

\footnotetext{
${ }^{9}$ Grillner, S., Markram, H., De Schutter, E., Silberberg, G. \& LeBeau, F. E. N. (2005) Microcircuits in action-from CPGs to neocortex. Trends Neurosci 28, 525-533.

${ }^{10}$ Ascoli, G. A. (2010) The coming of age of the hippocampome. Neuroinform 8, 1-3.

${ }^{11}$ Izhikevich, E. M. \& Edelman, G. M. (2008) Large-scale model of mammalian thalamocortical systems. Proc Natl Acad Sci USA 105, 3593-3598.

$12 \mathrm{http} / / /$ bluebrain.epfl.ch/page-58120-en.html

${ }^{13} \mathrm{http}: / / \mathrm{www} \cdot$ humanbrainproject.eu

${ }^{14} \mathrm{http}: / / \mathrm{www}$. nature.com/news/brain-simulation-and-graphene-projectswin-billion-euro-competition-1.12291

${ }^{15}$ De Schutter, E., Ascoli, G. A. \& Kennedy, D. N. (2006) On the future of the human brain project. Neuroinform 4, 129-130.

${ }^{16}$ Alivisatos, A. P. et al. (2012) The brain activity map project and the challenge of functional connectomics. Neuron 74, 970-974; http:// www.nytimes.com/2013/02/18/science/project-seeks-to-build-map-ofhuman-brain.html?hp\&_r=3\&
}

\footnotetext{
$\overline{{ }^{17} \mathrm{http} / / / \text { opensourcebrain.org }}$

${ }^{18}$ Migliore, M. et al. (2003) ModelDB: making models publicly accessible to support computational neuroscience. Neuroinform 1, 135-139.

${ }^{19}$ de Souza, F. \& De Schutter, E. (2011) Robustness effect of gap junctions between Golgi cells on cerebellar cortex oscillations. Neural Syst Circ 1, 7.

${ }^{20}$ Ascoli, G. A. (2006) The ups and downs of neuroscience shares. Neuroinform 4, 213-216.

${ }^{21}$ Kennedy, D. N. (2004) Barriers to the socialization of information. Neuroinform 2, 367-368.

${ }^{22}$ De Schutter, E. (2008) Why are computational neuroscience and systems biology so separate? PLoS Comp Biol 4, e1000078.
} 